\title{
High-Performance Aqueous Zinc-Ion Batteries Realized by MOF Materials
}

Cite as

Nano-Micro Lett.

(2020) 12:152

Received: 27 April 2020

Accepted: 18 June 2020

Published online: 17 July 2020

(C) The Author(s) 2020

\author{
Xuechao $\mathrm{Pu}^{1,2}$, Baozheng Jiang ${ }^{1,3}$, Xianli Wang ${ }^{1}$, Wenbao Liu ${ }^{1,2}$, Liubing Dong ${ }^{4}$, \\ Feiyu Kang ${ }^{1,2}$, Chengjun $\mathrm{Xu}^{1} \bowtie$ \\ $\triangle$ Liubing Dong, donglb@jnu.edu.cn; Chengjun Xu, vivaxuchengjun@163.com \\ 1 Shenzhen Geim Graphene Center, Tsinghua Shenzhen International Graduate School, Tsinghua University, \\ Shenzhen 518055, People's Republic of China \\ 2 State Key Laboratory of New Ceramics and Fine Processing, School of Materials Science and Engineering, \\ Tsinghua University, Beijing 100084, People's Republic of China \\ 3 Tsinghua-Berkeley Shenzhen Institute (TBSI), Tsinghua University, Shenzhen 518055, \\ People's Republic of China \\ 4 College of Chemistry and Materials Science, Jinan University, Guangzhou 511443, \\ People's Republic of China
}

\section{HIGHLIGHTS}

- Various MOF materials were synthesized and investigated as ZIB cathodes.

- A long-term stable ZIF-8@Zn anode was proposed by coating ZIF-8 material on the surface of zinc foils.

- High-performance aqueous ZIBs were constructed using the Mn(BTC) cathode and the ZIF-8@Zn anode.

\begin{abstract}
Rechargeable aqueous zinc-ion batteries (ZIBs) have been gaining increasing interest for large-scale energy storage applications due to their high safety, good rate capability, and low cost. However, the further development of ZIBs is impeded by two main challenges: Currently reported cathode materials usually suffer from rapid capacity fading or high toxicity, and meanwhile, unstable zinc stripping/plating on $\mathrm{Zn}$ anode seriously shortens the cycling life of ZIBs. In this paper, metal-organic framework (MOF) materials are proposed to simultaneously address these issues and realize high-performance ZIBs with Mn(BTC) MOF cathodes and ZIF-8-coated Zn (ZIF-8@ $\mathrm{Zn}$ ) anodes. Various MOF materials were synthesized, and Mn(BTC) MOF was found to exhibit the best $\mathrm{Zn}^{2+}$-storage ability with a capacity of $112 \mathrm{mAh} \mathrm{g}^{-1} . \mathrm{Zn}^{2+}$ storage

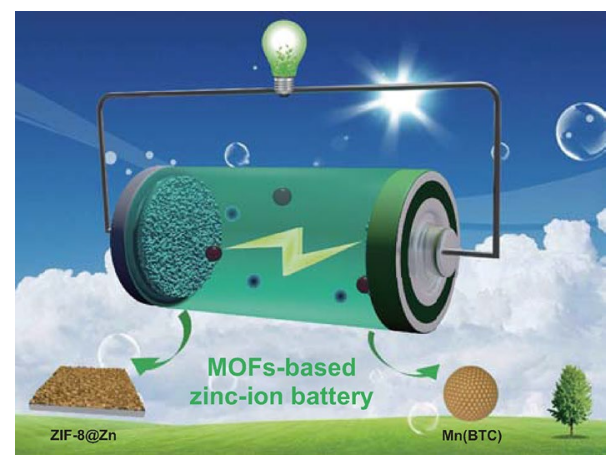
mechanism of the Mn(BTC) was carefully studied. Besides, ZIF-8@Zn anodes were prepared by coating ZIF-8 MOF material on Zn foils. Unique porous structure of the ZIF-8 coating guided uniform $\mathrm{Zn}$ stripping/plating on the surface of $\mathrm{Zn}$ anodes. As a result, the ZIF-8@Zn anodes exhibited stable Zn stripping/plating behaviors, with 8 times longer cycle life than bare Zn foils. Based on the above, high-performance aqueous ZIBs were constructed using the Mn(BTC) cathodes and the ZIF-8@Zn anodes, which displayed an excellent long-cycling stability without obvious capacity fading after 900 charge/discharge cycles. This work provides a new opportunity for high-performance energy storage system.
\end{abstract}

KEYWORDS Zinc-ion battery; Metal-organic framework; Cathode material; Zn anode 


\section{Introduction}

Lithium-ion batteries have been widely used in modern society [1]. However, security problems and increasing production cost pose challenges for their large-scale applications in the field of electric vehicles [2-4]. Researchers are committed to seeking alternative electrochemical energy storage systems to lithium-ion batteries. Many new-type rechargeable batteries using multivalent metal ions (e.g., $\mathrm{Zn}^{2+}, \mathrm{Mg}^{2+}$, and $\mathrm{Al}^{3+}$ ) as charge carriers have been proposed successively [5-7]. Among them, rechargeable aqueous zinc-ion batteries (ZIBs) have been considered as highly promising candidate for the next-generation energy storage system, because they are safe, low cost, and environmental benign [5]. In order to meet the demands of common energy consumption, two main issues should be addressed for the ZIBs. One is exploring suitable cathode materials for the reversible intercalation/extraction of zinc-ions [8, 9], and the other is exploring stable zinc metal anodes because this is essential for ZIBs to realize a long cycle life [10-13].

To find high-performance cathode materials for ZIBs, many attempts have been made [14]. Up to now, several types of ZIB cathode materials have been reported, including Mnbased materials [15-22], V-based materials [23-29], Prussian blue analogs [30-32], and some other cathode materials such as $\mathrm{Mo}_{6} \mathrm{~S}_{8}$ [33], quinone [34], and poly(benzoquinonyl sulfide) [35]. Mn-based materials, especially manganese oxides, possess the advantages such as low cost and environmental friendliness, but they suffer from the problems of rapid capacity fading and poor rate performance [36]. V-based cathode materials generally exhibit superior $\mathrm{Zn}^{2+}$-storage ability [37, 38], whereas serious toxicity limits their largescale applications for ZIBs [10]. The $\mathrm{Zn}^{2+}$-storage capacity of Prussian blue analogs is only about $50 \mathrm{mAh} \mathrm{g}^{-1}$, which determines that the Prussian blue analogs may be not qualified to construct high-energy ZIBs [30]. In view of the above discussion, developing high-performance cathode materials for ZIBs is still a challenge. Furthermore, metallic Zn electrode owns an ultrahigh volumetric capacity and low redox potential $(-0.76 \mathrm{~V}$ vs. standard hydrogen electrode), which enable it to be a promising anode for ZIBs [5, 39, 40]. However, in practical applications, repeated deposition/dissolution of $\mathrm{Zn}$ inclines to form zinc dendrites/protuberances, leading to severe polarization and a short circuit of the batteries [41]. Some modification strategies such as introducing additives, employing gel electrolyte, using 3D current collectors, and creating the protection layer have been proposed to regulate $\mathrm{Zn}$ stripping/plating behaviors and realized dendrite-free zinc metal anodes [11, 12, 42, 43]. In a word, stabilizing zinc anodes is also critical to realize long-life ZIBs.

Exploring new potential materials such as metal-organic frameworks (MOFs) may open opportunities for addressing these problems. MOFs are characterized by highly porous structure, designable frameworks, and multifunctionality [44-46]. In the past two decades, MOFs have been widely used in energy storage systems such as lithium-ion batteries [47], supercapacitors [48], and fuel cells [49]. Recently, MOFs are attracting increasing interests in the field of ZIBs. For instance, a $\mathrm{MnO}_{x} / \mathrm{N}$-doped carbon cathode material was synthesized based on a MOF template and provided a $\mathrm{Zn}^{2+}$-storage capacity of $305 \mathrm{mAh} \mathrm{g}^{-1}$ even after 600 charge/ discharge cycles [36]. Besides, a MOF-based single-ion $\mathrm{Zn}^{2+}$ solid-state electrolyte with high ionic conductivity, high $\mathrm{Zn}^{2+}$ transference number, and good electrochemical stability was designed to achieve dendrite-free $\mathrm{Zn}$ batteries [50]. These researches imply that MOFs may provide new opportunities to construct high-performance ZIBs.

Herein, we synthesized five kinds of MOFs materials, including $\mathrm{Mn}$ (BTC), $\mathrm{Mn}$ (BDC), $\mathrm{Fe}(\mathrm{BDC}), \mathrm{Co}(\mathrm{BDC})$, and $\mathrm{V}(\mathrm{BDC})$ (in which BDC is 1,4-dicarboxybenzene and BTC is 1,3,5-benzenetricarboxylic acid.) and investigated their electrochemical behaviors as ZIB cathodes. Among these MOFs materials, $\mathrm{Mn}$ (BTC) showed the best $\mathrm{Zn}^{2+}$ storage capability. $\mathrm{Zn}^{2+}$ storage mechanism of the $\mathrm{Mn}(\mathrm{BTC})$ cathode was then comprehensively studied. Besides, we developed a long-term stable ZIF-8@Zn anode by coating ZIF-8 material on the surface of zinc foils. Furthermore, high-performance aqueous ZIBs were constructed using the Mn(BTC) cathodes and the ZIF-8@Zn anodes, which exhibited an excellent cycling stability with $92 \%$ capacity retention after 900 charge/discharge cycles. This work opens up a new door for achieving high-performance aqueous zinc-ion batteries based on MOFs materials.

\section{Experimental Section}

\subsection{Synthesis of MOF Materials}

To synthesize $\mathrm{Mn}$ (BTC), $1225 \mathrm{mg} \mathrm{Mn}\left(\mathrm{CH}_{3} \mathrm{COO}\right)_{2} \cdot 4 \mathrm{H}_{2} \mathrm{O}$ and $300 \mathrm{mg}$ polyvinyl pyrrolidone (PVP) were dissolved 
in ethanol/ $\mathrm{H}_{2} \mathrm{O}(125 / 125 \mathrm{~mL})$ to get solution $\mathrm{A}$, and meanwhile, $2250 \mathrm{mg}$ trimesic acid $\left(\mathrm{H}_{3} \mathrm{BTC}\right)$ was dissolved in another ethanol/ $\mathrm{H}_{2} \mathrm{O}(125 / 125 \mathrm{~mL})$ system to get solution $\mathrm{B}$. Then, solution B was added slowly into solution A under continuous stirring. After $10 \mathrm{~min}$, the reaction mixture was aged without interruption for $24 \mathrm{~h}$. The products were collected after centrifugation, washing several times with ethanol and complete drying in an oven at $60^{\circ} \mathrm{C}$. $\mathrm{Fe}(\mathrm{BDC})$, $\mathrm{Mn}(\mathrm{BDC}), \mathrm{Co}(\mathrm{BDC})$, and $\mathrm{V}(\mathrm{BDC})$ were synthesized according to previously reported methods [51-55].

\subsection{Preparation of ZIF-8@Zn Anode}

ZIF-8 was purchased from J\&K Scientific Ltd. The asreceived ZIF-8 and polyvinylidene fluoride (PVDF) were mixed with a mass ratio of 8:2 in $N$-methyl-2-pyrrolidone (NMP) solvent to form a homogeneous slurry. Then, the slurry was uniformly coated onto a $\mathrm{Zn}$ foil and dried at $80^{\circ} \mathrm{C}$ overnight in a vacuum to obtain the ZIF-8-coated $\mathrm{Zn}$ (i.e., ZIF-8@Zn) anodes, in which the mass of the ZIF-8 coating was about $1.1 \mathrm{mg} \mathrm{cm}^{-2}$.

\subsection{Material Characterization}

Crystallographic and structure analysis was carried out by $\mathrm{X}$-ray diffraction (XRD, Rigaku 2500, $\mathrm{Cu} \mathrm{K} \alpha$ radiation, $\lambda=0.154056 \mathrm{~nm}$ ) with a scan rate of $5^{\circ} \mathrm{min}^{-1}$ over 2-theta ranging from $5^{\circ}$ to $70^{\circ}$. Field emission scanning electron microscopy (FE-SEM) was performed on a Zeiss Supra55 scanning electron microscope. Elemental analysis was characterized by energy-dispersive X-ray spectroscopy (EDS) on the FE-SEM. X-ray photoelectron spectroscopy (XPS, ESCALAB 250X, Thermo Fisher, United Kingdom) was used for characterizing the valence variation. Fourier transform infrared (FTIR, Thermo Scientific Nicolet iS 50) spectroscopy was used to identify functional groups in the MOF materials at pristine state and various charge/discharge states. Element content in electrolytes was analyzed by inductively coupled plasma atomic emission spectrometry (ICP-AES).

\subsection{Electrochemical Measurements of MOF Cathodes}

The electrochemical performance of various MOF cathodes was evaluated in CR2032 coin cells with zinc foil anode, air-laid paper separator, and $2 \mathrm{M} \mathrm{ZnSO}_{4}$ aqueous electrolyte. To prepare the MOF cathodes, the synthesized MOF powder was mixed with acetylene black and PVDF with a weight ratio of 7:2:1 in NMP solvent and then coated onto a stainless-steel current collector and dried at $80{ }^{\circ} \mathrm{C}$ overnight. The mass loading of MOF materials on current collectors is about $1.0 \mathrm{mg} \mathrm{cm}^{-2}$. For the assembled cells, cyclic voltammetry $(\mathrm{CV})$ tests were carried out on a VMP3 multichannel electrochemical station (Bio-Logic Science Instruments SA) at a sweep rate of $0.5 \mathrm{mV} \mathrm{s}^{-1}$, and galvanostatic charge-discharge (GCD) tests were performed on a LAND CT2001 battery tester at current density of $50 \mathrm{~mA} \mathrm{~g}^{-1}$.

\subsection{Electrochemical Measurements of ZIF-8@Zn Anodes}

Electrochemical behaviors of the ZIF-8@Zn anodes were characterized through ZIF-8@ZnIIZIF-8@Zn symmetrical cells, in which both the negative and positive electrodes were a ZIF-8@Zn disk (with diameter of $12 \mathrm{~mm}$ ), air-laid paper was used as the separator, and $2 \mathrm{M} \mathrm{ZnSO}_{4}$ (or $2 \mathrm{M}$ $\mathrm{ZnSO}_{4}+0.1 \mathrm{M} \mathrm{MnSO}_{4}$ ) aqueous solution was used as the electrolyte. For comparison, $\mathrm{Zn}\left\|\mathrm{ZnSO}_{4}\right\| \mathrm{Zn}$ symmetrical cells were also assembled, in which pure $\mathrm{Zn}$ foils served as $\mathrm{Zn}$ electrodes. Electrochemical stability of these symmetric cells was evaluated by GCD tests at different current densities of $0.25-2 \mathrm{~mA} \mathrm{~cm}^{-2}$ and different charge/discharge capacities of $0.05-0.4 \mathrm{mAh} \mathrm{cm}^{-2}$ on a LAND CT2001 battery tester. The impedance measurements of symmetrical cells were taken on a VMP3 multichannel electrochemical station (Bio-Logic Science Instruments SA) between $300 \mathrm{kHz}$ and $0.01 \mathrm{~Hz}$.

\subsection{Construction and Electrochemical tests of Mn(BTC) Cathode//ZIF-8@Zn Anode ZIBs}

The MOF//ZIF-8@Zn ZIBs were constructed based on the Mn(BTC) cathode, ZIF-8@Zn anode, an air-laid paper 
separator, and $2 \mathrm{M} \mathrm{ZnSO}_{4}$ (or $2 \mathrm{M} \mathrm{ZnSO}_{4}+0.1 \mathrm{M} \mathrm{MnSO}_{4}$ ) electrolyte. $\mathrm{CV}$ and GCD measurements were taken on the Bio-Logic VMP3 electrochemical station and the LAND CT2001 battery tester, respectively.

\section{Results and Discussion}

\subsection{Material Characterization and Electrochemical Properties of MOF Cathodes}

Structure and morphology of the as-synthesized MOF materials including $\mathrm{Mn}(\mathrm{BTC}), \mathrm{Mn}(\mathrm{BDC}), \mathrm{Fe}(\mathrm{BDC}), \mathrm{Co}(\mathrm{BDC})$, and $\mathrm{V}(\mathrm{BDC})$ were characterized by $\mathrm{X}$-ray diffraction (XRD) and scanning electron microscope (SEM). Figures 1a-e and S1 display that the $\mathrm{Mn}(\mathrm{BTC})$ and $\mathrm{Fe}(\mathrm{BDC})$ are composed of spherical and octahedral particles with size of $1-10 \mu \mathrm{m}$, respectively, and the other three MOF samples have irregular-shaped micromorphologies. As shown in Fig. If and Fig. S2, the XRD patterns of the synthesized MOF materials are consistent with previously reported literature [51-55], indicating that $\mathrm{Mn}$ (BTC), $\mathrm{Mn}(\mathrm{BDC}), \mathrm{Fe}(\mathrm{BDC}), \mathrm{Co}(\mathrm{BDC})$, and $\mathrm{V}(\mathrm{BDC}) \mathrm{MOF}$ were successfully synthesized. The crystalline structures of these MOF materials are depicted in Fig. S3.
To evaluate $\mathrm{Zn}^{2+}$-storage ability of the above MOF materials as ZIB cathodes, cyclic voltammetry (CV) and galvanostatic charge-discharge (GCD) tests were conducted in $2 \mathrm{M} \mathrm{ZnSO}_{4}$ aqueous electrolyte. These MOF materials are selected as ZIB cathodes because the transition metal centers of $\mathrm{Mn}, \mathrm{Fe}, \mathrm{Co}$, and $\mathrm{V}$ have proved to be active sites in electrochemical energy storage systems [56-60]. Meanwhile, $\mathrm{BDC}$ and BTC ligands are conventional ligands for MOF materials, and their lightweight feature is beneficial for the MOF materials to achieve a higher theoretical capacity considering that ligands usually cannot be redox sites for metalion storage [61]. Corresponding CV curves are shown in Fig. 2a-e. For the Mn(BTC) cathode, it can operate in a voltage window of $1.0-1.9 \mathrm{~V}$ (vs. $\mathrm{Zn}^{2+} / \mathrm{Zn}$ ), and reversible redox peaks are observed on the $\mathrm{CV}$ curves (Fig. 2a), preliminarily demonstrating effective $\mathrm{Zn}^{2+}$ storage in the $\mathrm{Mn}(\mathrm{BTC})$. For the $\mathrm{CV}$ curves of the $\mathrm{Mn}(\mathrm{BDC})$ and $\mathrm{Fe}(\mathrm{BDC}) \mathrm{MOF}$ cathodes in Fig. 2b, c, there also emerge 1-3 pairs of reversible redox peaks, but the peak currents of the $\mathrm{Fe}$ (BDC) MOF are much smaller. The redox peaks in the $\mathrm{CV}$ curves of the $\mathrm{Co}(\mathrm{BDC})$ and $\mathrm{V}(\mathrm{BDC})$ are not obvious, and response currents are very small (Fig. 2d, e), suggesting a poor $\mathrm{Zn}^{2+}$-storage ability. Figure $2 \mathrm{f}$ displays charge/discharge curves at a current of $50 \mathrm{~mA} \mathrm{~g}^{-1}$ of the five MOF cathode materials. The
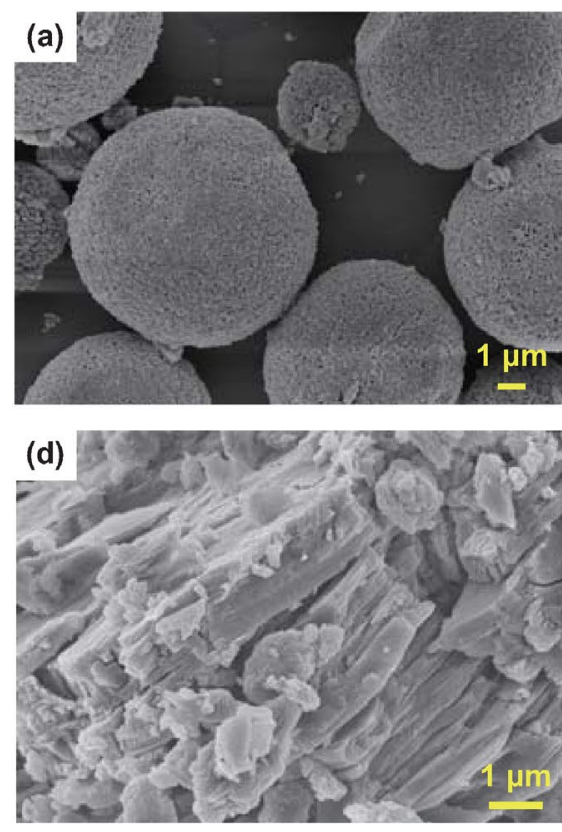

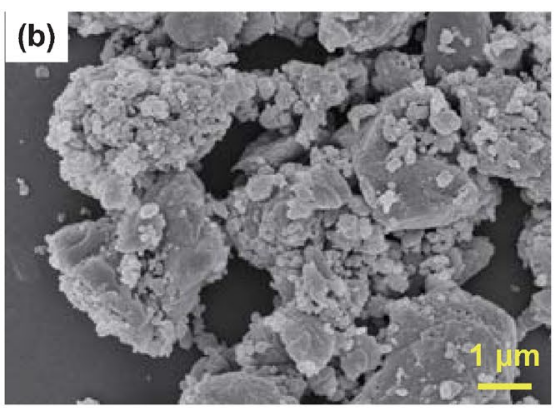

(e)

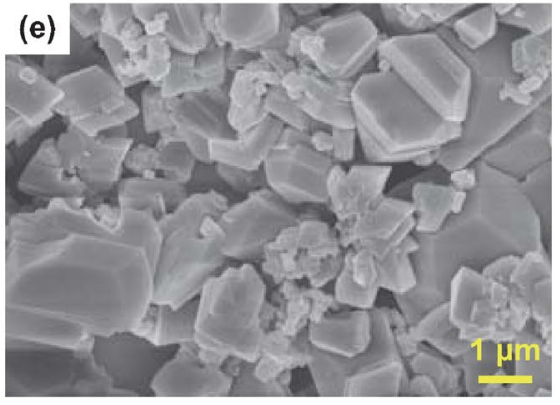

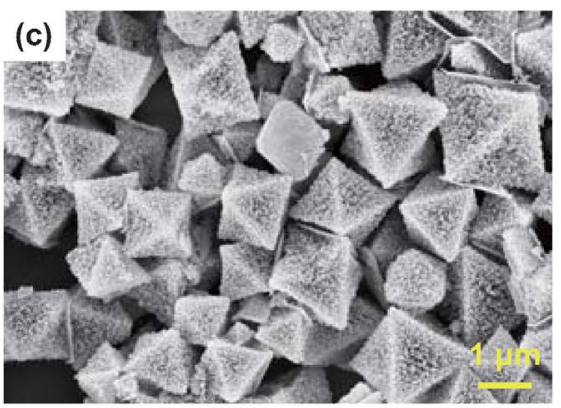

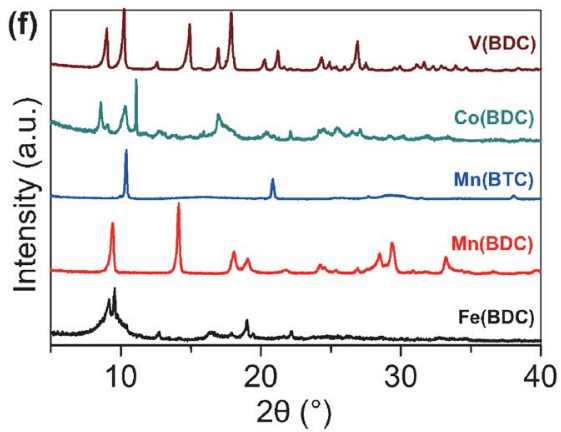

Fig. 1 SEM images of the synthesized MOF materials: a Mn(BTC), b Mn(BDC), $\mathbf{c} F(B D C), \mathbf{d} \mathrm{Co}(\mathrm{BDC})$, and e V(BDC), $\mathbf{f}$ XRD patterns of the samples 

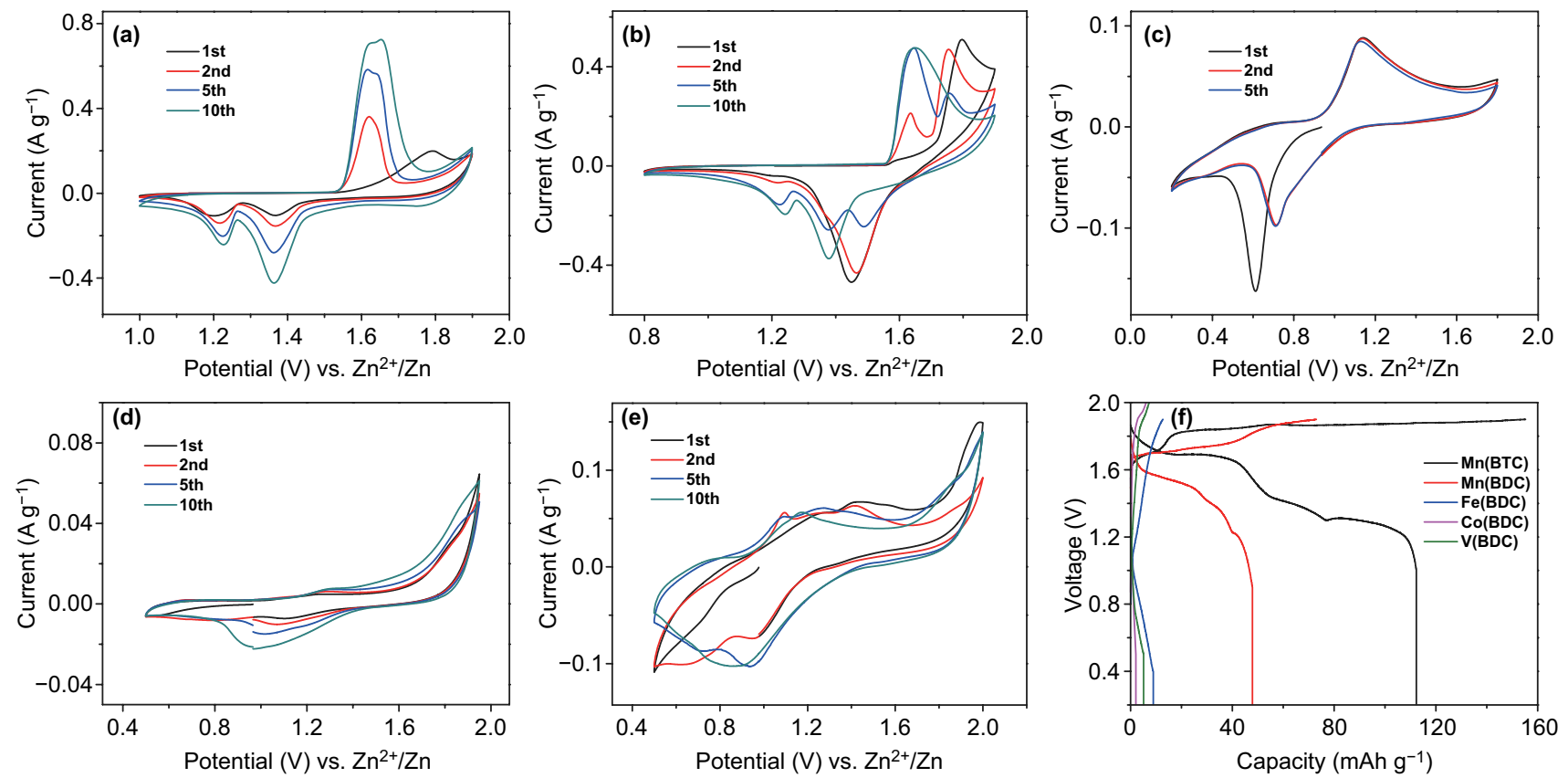

Fig. $2 \mathrm{CV}$ curves at $0.5 \mathrm{mV} \mathrm{s}^{-1}$ of the MOF cathodes: a Mn(BTC), b Mn(BDC), c Fe(BDC), d Co(BDC), and e V(BDC), f Charge/discharge curves at $50 \mathrm{~mA} \mathrm{~g}^{-1}$ of the MOF cathodes

Mn(BTC) exhibits several voltage plateaus in its discharge curve and delivers the highest $\mathrm{Zn}^{2+}$-storage capacity of $112 \mathrm{mAh} \mathrm{g}^{-1}$. Specific capacity of the $\mathrm{Mn}(\mathrm{BDC})$ cathode is about $48 \mathrm{mAh} \mathrm{g}^{-1}$. In contrast, the other three MOF cathodes including $\mathrm{Fe}(\mathrm{BDC}), \mathrm{Co}(\mathrm{BDC})$, and $\mathrm{V}(\mathrm{BDC})$ are incapable of effectively storing $\mathrm{Zn}^{2+}$, which is reflected by their very low capacities of less than $10 \mathrm{mAh} \mathrm{g}^{-1}$. Obviously, for the above MOF samples, only Mn(BTC) is promising to be utilized as a high-performance cathode material for ZIBs. Despite this, the $\mathrm{Mn}(\mathrm{BTC})$ shows a modest cycling stability during repeated $\mathrm{Zn}^{2+}$ storage-release processes (Fig. S4). This issue needs to be resolved based on the reveal of $\mathrm{Zn}^{2+}$-storage mechanism of the $\mathrm{Mn}$ (BTC) cathode.

\subsection{Energy Storage Mechanism of the Mn(BTC) Cathode}

$\mathrm{Zn}^{2+}$-storage mechanism of the $\mathrm{Mn}$ (BTC) cathode in $\mathrm{ZnSO}_{4}$ electrolyte is further investigated. Evolution of the phase composition and micromorphology of the $\mathrm{Mn}$ (BTC) electrode during $\mathrm{Zn}^{2+}$ storage-release processes were characterized by XRD and SEM, as shown in Fig. 3. When the fresh $\mathrm{Mn}$ (BTC) cathode is charged to $1.9 \mathrm{~V}$ at $50 \mathrm{~mA} \mathrm{~g}^{-1}$, "nanoflower-like" and "rod-like" particles appear
(Fig. 3b). The "nanoflower" particles densely distribute on the surface of the electrode. Energy-dispersive X-ray spectroscopy (EDS) analysis in Fig. S5 points out that the "nanoflower" particles contain $\mathrm{Mn}$ and $\mathrm{O}$ elements, and the main composition elements of the "rod-like" particles are $\mathrm{C}, \mathrm{O}$, and $\mathrm{Zn}$. When the $\mathrm{Mn}$ (BTC) cathode is then discharged to $1.0 \mathrm{~V}$ (Fig. 3c), the "rod-like" particles still exist, but the "nanoflower-like" particles disappear, and meanwhile, some large flakes form. The XRD results of the cathode at different charge-discharge states are shown in Fig. 3d. Compared with the original state, XRD pattern of the $\mathrm{Mn}$ (BTC) cathode at the fully charged state (i.e., $1.9 \mathrm{~V}$ ) shows obvious differences. The main peaks (at $10.4^{\circ}, 20.8^{\circ}, 29.4^{\circ}, 38.0^{\circ}$, and $42.4^{\circ}$ ) of the $\mathrm{Mn}$ (BTC) disappear, and some new peaks emerge (at $17.5^{\circ}, 18.6^{\circ}$, $21.9^{\circ}, 26.4^{\circ}, 27.0^{\circ}$, and $35.5^{\circ}$ ), which means that there arises a phase transition reaction and new phases form undergoing charging. XRD pattern at the fully discharged state (i.e., $1.0 \mathrm{~V}$ ) shows the characteristic diffraction peaks of $\mathrm{ZnSO}_{4} \cdot 3 \mathrm{Zn}(\mathrm{OH})_{2} \cdot 5 \mathrm{H}_{2} \mathrm{O}$ (denoted as BZSP). Therefore, the above-mentioned large flakes in Fig. $3 \mathrm{c}$ are considered as BZSP. Besides, from the fully charged state to the fully discharged state, some diffraction peaks (e.g., at $17.5^{\circ}$, $18.6^{\circ}, 26.4^{\circ}, 27.0^{\circ}$, and $35.5^{\circ}$ ) of the cathode remain 

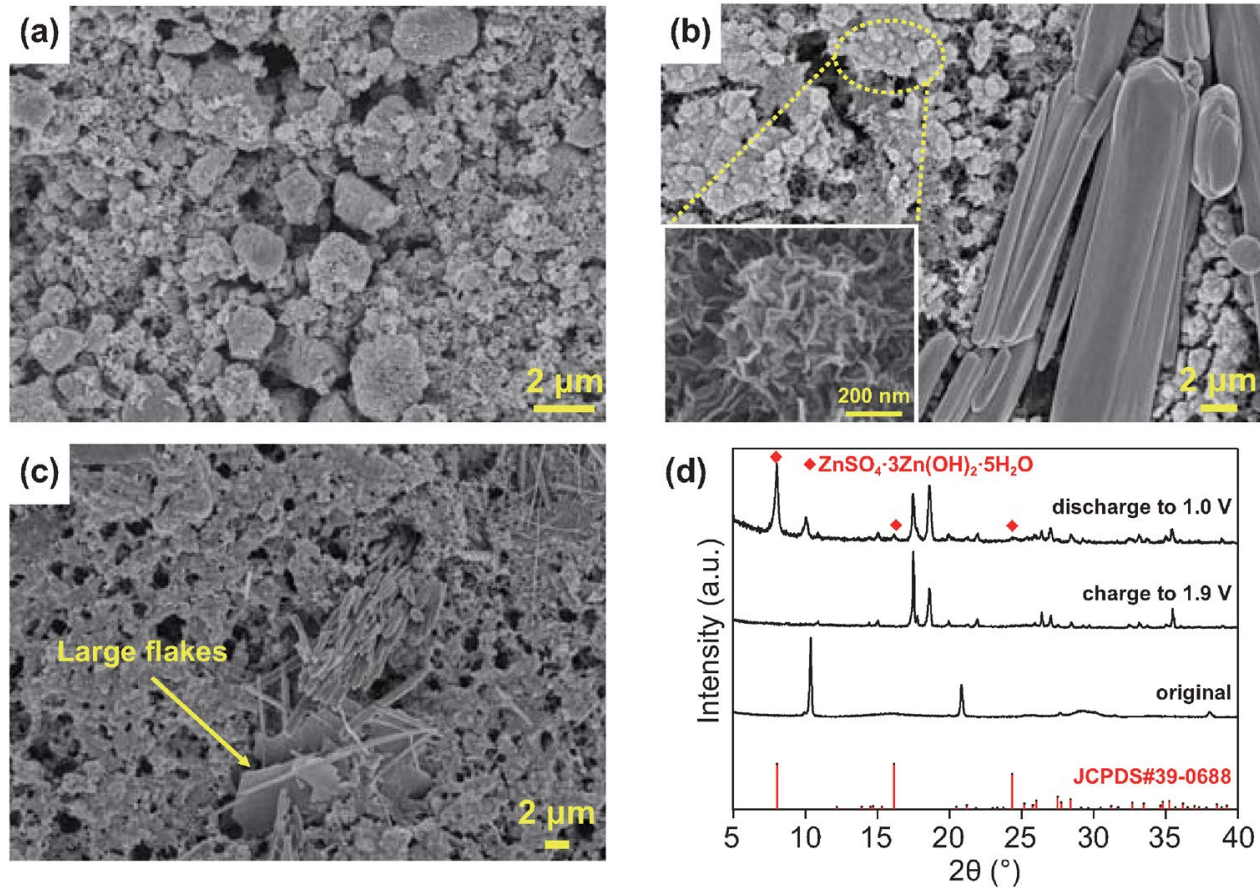

Fig. 3 SEM images of Mn(BTC) cathode at different states: a original state, $\mathbf{b}$ charge to $1.9 \mathrm{~V}$ and $\mathbf{c}$ discharge to $1.0 \mathrm{~V}$. Inset in $\mathbf{b}$ is a highresolution SEM image of the encircled zone. $\mathbf{d}$ XRD patterns of the cathode at the above states

unchanged positions. No PDF cards of $\mathrm{MnO}_{2}$ can match well with these diffraction peaks, and they still remain their positions at the fully discharged state, so these diffraction peaks do not belong to $\mathrm{MnO}_{2}$. These diffraction peaks are thought to originate from the "rod-like" particles that are observed in Fig. 3b, c.

To figure out what the "rod-like" and "nanoflower-like" compounds (Fig. 3b, c) are, X-ray photoelectron spectroscopy (XPS) and Fourier transform infrared spectroscopy (FTIR) were further carried out in Fig. 4. The high-resolution Mn $2 p$ XPS spectrum of the Mn(BTC) cathode at fully charged state (Fig. 4a) shows that the Mn $2 p_{3 / 2}$ and Mn $2 p_{1 / 2}$ peaks situate at 642.1 and $653.8 \mathrm{eV}$, respectively, with the peak separation of $11.7 \mathrm{eV}$. These values are consistent with the reported parameters for $\mathrm{MnO}_{2}$ [62-65]. Considering that these "nanoflower-like" particles contain Mn element while "rod-like" particles do not (as discussed in Fig. S5a), the "nanoflower-like" particles are determined to be $\mathrm{MnO}_{2}$. In Fig. 4b, peak separation of $\mathrm{Mn}$ $3 s$ orbit decreases from $6.4 \mathrm{eV}$ for the original Mn(BTC) cathode to $4.7 \mathrm{eV}$ for the fully charged $\mathrm{Mn}$ (BTC) cathode, indicating the increase in the Mn oxidation state after charging process [19]. The O $1 s$ core-level spectrum in Fig. $4 \mathrm{c}$ can be divided into four main peaks. Especially, the peak centered at $529.7 \mathrm{eV}$ is in accord with the typical bond of Mn-O-Mn [66].

FTIR spectra of the $\mathrm{Mn}(\mathrm{BTC})$ cathode at original, charging, and discharging states are presented in Fig. 4d. In the FTIR spectrum of the original $\mathrm{Mn}(\mathrm{BTC})$, the absorption peaks of $\mathrm{O}-\mathrm{H}$ at $3082 \mathrm{~cm}^{-1}$ and $\mathrm{C}=\mathrm{O}$ at $1720 \mathrm{~cm}^{-1}$ from 1,3,5-benzenetricarboxylic acid disappear, while the asymmetric stretching vibrations of - $\mathrm{COO}-$ and symmetric stretching vibrations of - $\mathrm{COO}-$ are detected in the regions of 1612-1545 and 1433-1372 $\mathrm{cm}^{-1}$, respectively. This is an evidence that the manganese ions have been successfully coordinated with the 1,3,5-BTC ligands in the $\mathrm{Mn}$ (BTC) material [56]. When the $\mathrm{Mn}$ (BTC) is charged to $1.9 \mathrm{~V}$, the asymmetric stretching vibration of $-\mathrm{COO}-$ at $1612 \mathrm{~cm}^{-1}$ shifts to a new band at $1628 \mathrm{~cm}^{-1}$. Meanwhile, the symmetric stretching vibration of $-\mathrm{COO}-$ at $1372 \mathrm{~cm}^{-1}$ shifts to a new band at $1383 \mathrm{~cm}^{-1}$. They are coordination characteristic bands of $\mathrm{Zn}$ (BTC) MOF materials [67]. These suggest that zinc-ion substitute manganese-ion to be coordinated with - $\mathrm{COOH}$ to form $\mathrm{Zn}$ (BTC). When the $\mathrm{Mn}(\mathrm{BTC})$ cathode is then discharged to $1.0 \mathrm{~V}$, there is no 

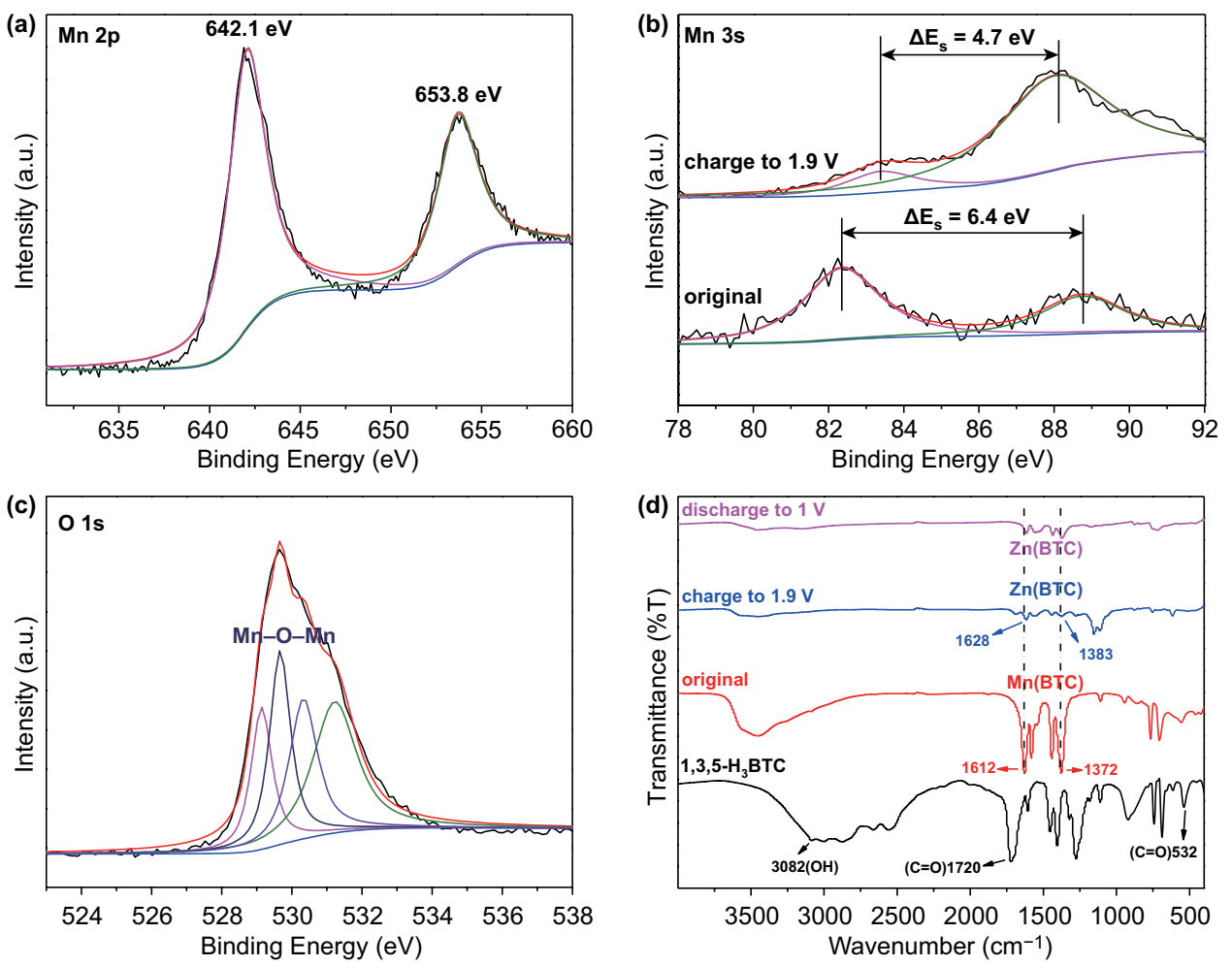

Fig. 4 XPS spectra of the Mn(BTC) cathode at fully charged state: a Mn $2 p$, b Mn $3 s$, and c O $1 s$. Mn $3 s$ XPS spectrum of the original $\mathrm{Mn}$ (BTC) cathode is also presented in b. d FTIR spectra of 1,3,5- $\mathrm{H}_{3} \mathrm{BTC}$, original Mn(BTC) cathode, $\mathrm{Mn}(\mathrm{BTC})$ cathode at 1.9 and $1.0 \mathrm{~V}$

distinct change for these typical bands, suggesting that $\mathrm{Zn}$ (BTC) remains stable during discharge process.

Based on the above analysis, we speculate possible reaction paths of the $\mathrm{Mn}$ (BTC) cathode during charge-discharge processes. During the first charge process, there occurs a transformation from $\mathrm{Mn}(\mathrm{BTC})$ to $\mathrm{Zn}(\mathrm{BTC})$, and $\mathrm{Mn}^{2+}$ dissolves into electrolyte. These $\mathrm{Mn}^{2+}$ is oxidized to $\mathrm{MnO}_{2}$ on the cathode surface through a normal manganese deposition reaction as the charging process proceeds. The reaction paths were further confirmed by plasma atomic emission spectrometry (ICP-AES) tests. As shown in Table S1, Mn element concentration in electrolyte was detected when the cathode was charged/discharged to various states. Mn element concentration in electrolyte is 6.15 and $4.62 \mathrm{mg} \mathrm{L}^{-1}$ when the cathode is charged to 1.8 and $1.9 \mathrm{~V}$, respectively. Decrease in Mn concentration in electrolyte is attributed to manganese deposition reaction. Subsequently, the deposited $\mathrm{MnO}_{2}$ serves as a host for $\mathrm{Zn}^{2+}$ and $\mathrm{H}^{+}$storage in the following charge/discharge processes, which is the reason that we detected the formation of BZSP during charge/discharge processes (Fig. 3c, d) [68]. It worth noting that the BTC organic ligands of $\mathrm{Mn}$ (BTC) cathodes are not involved in the $\mathrm{Zn}$-storage redox process, not only because the BTC ligands have been proved to be redox-innocent ligands [61] but also because they are always detected during charge/ discharge processes of our ZIB systems (which means that BTC would not directly participate in Zn-storage reactions). However, BTC ligand is an indispensable part of Mn(BTC) because it constructs the three-dimensional framework of MOF materials. Interestingly, as shown in Fig. S6, Zn(BTC) particles seem to be the main by-product in this system and the formation of BZSP by-product is suppressed in this system compared with previously reported $\mathrm{MnO}_{2}$ cathode [68]. Unlike densely arranged BZSP flakes generated in $\mathrm{MnO}_{2} / /$ Zn ZIBs [68], these rod-like Zn(BTC) particles (generated in $\mathrm{Mn}$ (BTC)//Zn ZIBs) do not impede the direct contact between electrolyte and electrode materials, which is beneficial to ions diffusion and prolonged cycle life of the ZIBs.

In the above-proposed reaction pathways, the oxidation reaction from $\mathrm{Mn}$ (BTC) to $\mathrm{MnO}_{2}$ plays an important role in this system. On the one hand, $\mathrm{MnO}_{2}$ is capable of delivering a high capacity, but on the other hand, $\mathrm{MnO}_{2}$ generally suffers from rapid capacity fading due to the dissolution of manganese from the $\mathrm{MnO}_{2}$ electrode [15]. Therefore, the 
poor cycling stability of the $\mathrm{Mn}(\mathrm{BTC}) / / \mathrm{ZnSO}_{4} / / \mathrm{Zn}$ system as discussed in Fig. S4 is considered to be mainly caused by the dissolution of $\mathrm{MnO}_{2}$.

\subsection{MOF Material Stabilized Zn Metal Anodes}

To achieve stable zinc anodes, we introduced a ZIF-8 coating on bare $\mathrm{Zn}$ foil. Electrochemical stability of the ZIF8-coated Zn foil electrode (i.e., ZIF-8@Zn)was characterized in symmetrical ZIF-8@ZnIIZIF-8@Zn coin cells at a current density of $0.25 \mathrm{~mA} \mathrm{~cm}^{-2}$ and a charge/discharge capacity of $0.05 \mathrm{mAh} \mathrm{cm}^{-2}$. Figure 5 a shows the cycling performance of bare $\mathrm{Zn}$ foil electrode and the ZIF-8@Zn electrode based symmetric cells with $2 \mathrm{M} \mathrm{ZnSO}_{4}$ electrolyte. It can be seen that a sudden short circuit appears after $\sim 20 \mathrm{~h}$ stripping/plating for bare Zn foil. By contrast, the ZIF-8@ Zn electrode works stably for at least $170 \mathrm{~h}$ and corresponding polarization voltage almost keeps constant, implying that the ZIF-8@Zn electrode has superior cycle stability. Furthermore, compared with the first cycle charge/discharge profile of the bare Zn foil in Fig. 5b, the ZIF-8@Zn electrode demonstrates a lower polarization voltage (120 vs. $200 \mathrm{mV}$ for the bare $\mathrm{Zn}$ foil-based symmetric cells), which indicates a low energy barrier for metal nucleation on the surface of the ZIF-8@Zn electrode [69]. Very similarly, in the electrolyte of $2 \mathrm{M} \mathrm{ZnSO}_{4}+0.1 \mathrm{M} \mathrm{MnSO}_{4}$ mixture solution (Fig. 5c, d), the ZIF-8@Zn electrode-based symmetric cells exhibit small polarization voltages and a long-term stable charge/ discharge behavior over $170 \mathrm{~h}$, whereas the bare $\mathrm{Zn}$ foil electrode-based symmetric cells perform poorly. The remarkably improved cycling stability of the ZIF-8@Zn anode are also observed at larger current densities of $0.5-2 \mathrm{~mA} \mathrm{~cm}^{-2}$ and higher Zn deposited depth of 0.1-0.4 $\mathrm{mAh} \mathrm{cm}^{-2}$ (Fig. S7). All batteries exhibit stable cycling life over $150 \mathrm{~h}$, further confirming the benefits of the ZIF-8@Zn anode on Zn stripping/plating behaviors. Besides, electrochemical impedance spectroscopy (EIS) test was also conducted to study the interfacial properties of bare Zn and ZIF-8@Zn anodes. As shown in Fig. S8, bare Zn electrodes delivered a large interfacial resistance and charge transfer resistance (estimated from the semicircle arc at high frequency range), which is due to passivation surface layers on $\mathrm{Zn}$ foils [70]. By contrast, the ZIF-8@Zn electrodes show a smaller interfacial resistance since the ZIF- 8 coating provides a more stable
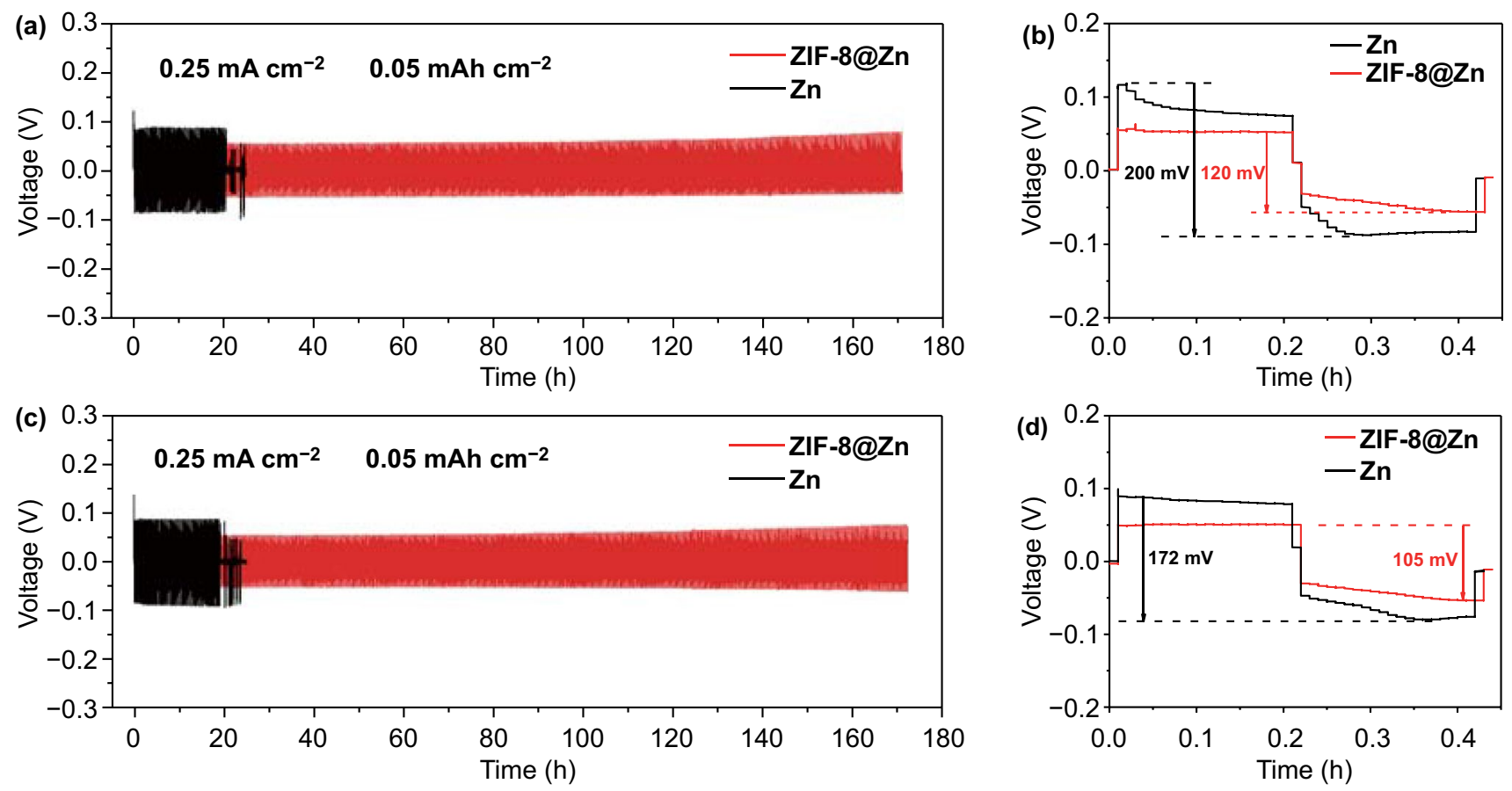

Fig. 5 Cycling performance of symmetrical cells with bare $\mathrm{Zn}$ foil and ZIF-8@Zn electrodes in a and b 2 M ZnSO $\mathbf{~}_{4}$ and $\mathbf{c}$ and $\mathbf{d} 2 \mathrm{M}$ $\mathrm{ZnSO}_{4}+0.1 \mathrm{M} \mathrm{MnSO}_{4}$ electrolytes. Applied current density is $0.25 \mathrm{~mA} \mathrm{~cm}^{-2}$ with $\mathrm{Zn}$ deposition/dissolution capacity of $0.05 \mathrm{mAh} \mathrm{cm}^{-2}$. b, d The first-cycle voltage profiles of symmetrical cells with bare $\mathrm{Zn}$ foil and ZIF-8@Zn electrodes 
electrode interface to guide a uniform Zn stripping/plating process.

Potential mechanism for the optimized electrochemical performance of the ZIF-8@ Zn electrode is further investigated. We analyzed the morphology evolution of the bare $\mathrm{Zn}$ foil electrode and the ZIF-8@Zn electrode before and after 100 charge/discharge cycles by SEM and EDS mapping. As shown in Fig. 6a, b, many large protuberances appear on the surface of the $\mathrm{Zn}$ foil after cycling, suggesting uneven zinc plating/stripping process during repeated charge/discharge cycles. EDS mapping in Fig. 6c and Fig. S9 demonstrates that these protuberances contain $\mathrm{O}$ and $\mathrm{Zn}$ elements; thus, they are zinc oxides/hydroxides, as reported in the literature [11]. Cross-sectional SEM image (Fig. S10a, b) further
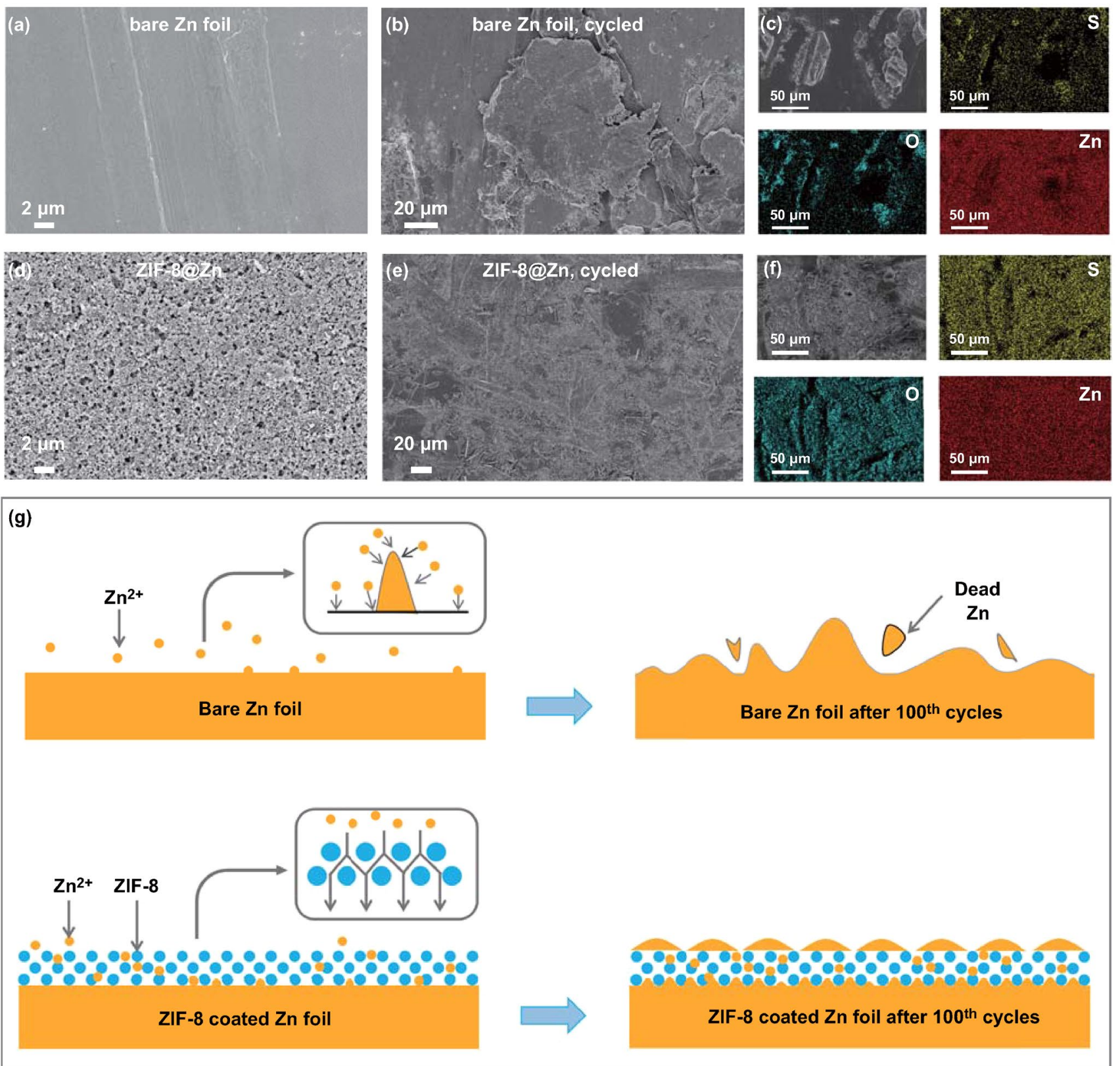

Fig. 6 SEM images and EDS mapping of bare Zn electrode a before and $\mathbf{b}$, $\mathbf{c}$ after 100 stripping/plating cycles, ZIF-8@Zn electrode d before, and $\mathbf{e}, \mathbf{f}$ after 100 stripping/plating cycles. $\mathbf{g}$ Schematic illustration for morphology change of the bare Zn foil and ZIF-8@Zn electrodes during repeated $\mathrm{Zn}$ stripping/plating processes 
shows some dead $\mathrm{Zn}$ particles on the surface of the bare $\mathrm{Zn}$ foil after cycling. In Fig. 6d, we can see that porous ZIF-8 coating is on the surface of the ZIF-8@Zn electrode, and after cycling (Fig. 6e, f), no large protuberances/dendrites appear. Besides, cross-sectional SEM and EDS images of the ZIF-8@Zn electrode (Fig. S10c, d) show that ZIF-8 layer does not fall off the $\mathrm{Zn}$ foil after 100 cycles, which means the ZIF-8 coating is stable in ZIBs. A schematic illustration for the morphology evolution of bare Zn and ZIF-8@Zn electrodes during repeated $\mathrm{Zn}$ stripping/plating is presented in Fig. 6g. According to the literature [71-74], Zn inclines to deposit on some sites to form small protuberances/dendrites during the plating process. These small protuberances/dendrites then generate inhomogeneous electric field, which is apt to attract $\mathrm{Zn}^{2+}$ to grow into uncontrolled protuberances/ dendrites. When stripping, these large protuberances/dendrites incline to dissolve from their root positions, leading to the formation of "dead" Zn. Furthermore, the vigorously growing zinc protuberances/dendrites may easily pierce through the separator and cause a short circuit. For ZIF-8@ $\mathrm{Zn}$ electrodes, the porous structure of ZIF- 8 coating can homogenize the zinc-ion flux, avoiding an uneven distribution of the electric field and thus inhibiting the formation of protuberances/dendrites [75-77].

\subsection{ZIBs of Mn(BTC) Cathode//ZIF-8@Zn Anode}

An aqueous zinc-ion battery using the above-studied Mn(BTC) cathode and ZIF-8@Zn anode was constructed, as illustrated in Fig. 7a. $2 \mathrm{M} \mathrm{ZnSO}_{4}$ aqueous solution was chosen as the electrolyte. $\mathrm{CV}$ curves at a scan rate of $0.5 \mathrm{mV} \mathrm{s}^{-1}$ are displayed in Fig. 7b. It can be seen that there emerge two reduction peaks at 1.22 and $1.37 \mathrm{~V}$ and one oxidation peak at $1.83 \mathrm{~V}$ in the initial cycle, and the oxidation peak is corresponding to the oxidation reaction from $\mathrm{Mn}$ (BTC) to $\mathrm{MnO}_{2}$ as discussed above. From the second cycles, two pairs of reversible redox peaks appear, indicating a reversible $\mathrm{Zn}^{2+}$ storage/release process. The rate performance is displayed in Fig. 7 c. The battery delivers a discharge capacity of 112,63 , 40 , and $14 \mathrm{mAh} \mathrm{g}^{-1}$, respectively, at current densities of 50, 100,200 , and $500 \mathrm{~mA} \mathrm{~g}^{-1}$. Figure $7 \mathrm{~d}$ shows cycling performance of the battery. It can be observed that the $\mathrm{Mn}$ (BTC) exhibits a discharge capacity of about $55 \mathrm{mAh} \mathrm{g}^{-1}$ at a current density of $100 \mathrm{~mA} \mathrm{~g}^{-1}$ after activation process. However, the capacity rapidly fades to only $27 \mathrm{mAh} \mathrm{g}^{-1}$ after 50 charge/discharge cycles, indicating a poor cycling stability. As investigated above, such a poor cycling performance can be mainly ascribed to the dissolution of $\mathrm{MnO}_{2}$ from $\mathrm{Mn}$ (BTC) cathode. Therefore, to optimize cycling performance of the $\mathrm{Mn}$ (BTC) cathode and the assembled battery, $\mathrm{MnSO}_{4}$ was added to the $\mathrm{ZnSO}_{4}$ electrolyte, because $\mathrm{Mn}^{2+}$ in the electrolyte is able to suppress manganese dissolution [78, 79]. In $2 \mathrm{M} \mathrm{ZnSO}_{4}+0.1 \mathrm{M} \mathrm{MnSO}_{4}$ electrolyte, their electrochemical performance is significantly improved. As shown in Fig. 7e, peak currents of CV curves with the addition of $\mathrm{Mn}^{2+}$ in the electrolyte are much higher than that without $\mathrm{Mn}^{2+}$ (Fig. 7b), which indicates a better $\mathrm{Zn}^{2+}$-storage ability. A superior rate capability is also achieved in Fig. 7f, with the capacity of $170,142,80$, and $46 \mathrm{mAh} \mathrm{g}^{-1}$ at current densities of $50,100,500$, and $1000 \mathrm{~mA} \mathrm{~g}^{-1}$, respectively. The high rate performance could be ascribed to the stabilization and excellent kinetics of the cathode under the case of $\mathrm{Mn}^{2+}$ addition in $\mathrm{ZnSO}_{4}$ electrolyte [15]. Cycling performance test (Fig. 7g) shows that the battery delivers a reversible capacity of $150 \mathrm{mAh} \mathrm{g}^{-1}$ after 50 cycles at $0.1 \mathrm{~A} \mathrm{~g}^{-1}$. Furthermore, the battery exhibits $92 \%$ capacity retention after 900 cycles at $1000 \mathrm{~mA} \mathrm{~g}^{-1}$ in Fig. 7h, which indicates excellent longcycling stability. It is worth noting that the cycle performance of $\mathrm{Mn}$ (BTC) cathode in $\mathrm{ZnSO}_{4}+\mathrm{MnSO}_{4}$ electrolyte is superior to many previously reported manganese oxide cathodes shown in Table $\mathrm{S} 2$ at similar current densities, but the capacity and rate capability are not as good as widely studied $\mathrm{MnO}_{2}$ materials. Despite this, MOF cathode materials are still promising for $\mathrm{Zn}^{2+}$ storage because further research may find some Mn-MOF or other MOF materials with much better $\mathrm{Zn}^{2+}$-storage ability, considering that MOF materials possess diverse structure, controllable chemical composition, very high specific surface area, and many other merits. CV curves (Fig. S11a) at various scan rates were also recorded and used to analyze $\mathrm{Zn}^{2+}$ storage kinetics of the cathode. When the scan rate increases from 0.5 to $5 \mathrm{mV} \mathrm{s}^{-1}$, both anodic and cathodic peaks slightly shift, which is due to increased polarization at higher scan rates [80]. According to the previous literature, the relationship between peak current $(i)$ and the scan rate $(v)$ can be represented by Eqs. 1 and 2 [81]:

$i=a v^{b}$

$\log i=b \log v+\log a$ 
(a)
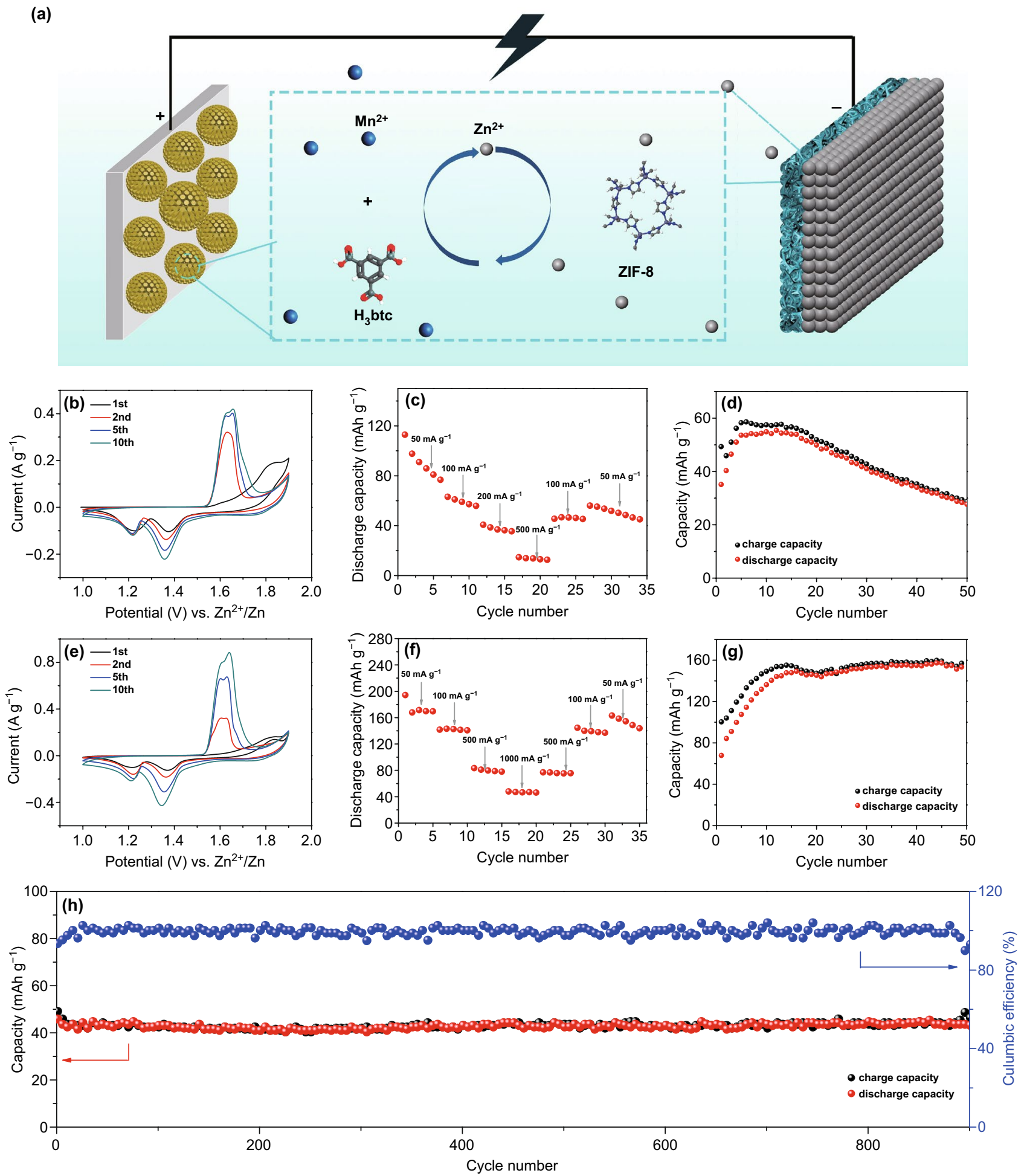

Fig. 7 a Schematic of the Mn(BTC) cathode//ZIF-8@Zn anode ZIBs. Electrochemical performance of the ZIBs: b CV curves at $0.5 \mathrm{mV} \mathrm{s}^{-1}$, c rate capability, and $\mathbf{d}$ cycling performance at $100 \mathrm{~mA} \mathrm{~g}^{-1}$ in $2 \mathrm{M} \mathrm{ZnSO}_{4}$ electrolyte; e CV curves at $0.5 \mathrm{mV} \mathrm{s}^{-1}$, f rate capability and cycling performance at $\mathbf{g}$ at $100 \mathrm{~mA} \mathrm{~g}^{-1}$, and $\mathbf{h}$ at $1000 \mathrm{~mA} \mathrm{~g}^{-1}$ in $2 \mathrm{M} \mathrm{ZnSO}_{4}+0.1 \mathrm{M} \mathrm{MnSO}_{4}$ electrolyte 
where $a$ and $b$ are adjustable parameters. In general, $b$ value ranges from 0.5 to 1.0 . The coefficient $b$ of 0.5 indicates a faradic reaction, and the coefficient $b$ of 1.0 means a complete surface-controlled capacitive process [82]. The $b$ values calculated by slope of the $\log (v)-\log (i)$ plots (Fig. S11b) for redox peaks (Fig. S11a) are 0.54 and 0.67 . This indicates that $\mathrm{Zn}^{2+}$ storage in the $\mathrm{Mn}(\mathrm{BTC})$ cathode is mainly through faradic reactions.

\section{Conclusions}

In summary, a high-performance aqueous zinc-ion battery system was realized based on MOF materials. Several kinds of MOF materials were synthesized first and investigated as cathode materials for ZIBs. During them, Mn(BTC) MOF showed a high capacity and its $\mathrm{Zn}^{2+}$ storage mechanism was revealed such as a transformation reaction from $\mathrm{Mn}(\mathrm{BTC})$ to $\mathrm{MnO}_{2}$ during charge process. In addition, a porous ZIF-8 coating was utilized to protect $\mathrm{Zn}$ foil anodes, which led to a uniform electrolyte flux and significantly inhibited the formation of zinc protuberances/dendrites. An aqueous zinc-ion battery was constructed based on the $\mathrm{Mn}$ (BTC) cathode and the ZIF- 8 stabilized $\mathrm{Zn}$ anode. Benefiting from the synergetic effect of $\mathrm{Mn}$ (BTC) cathode and $\mathrm{Mn}^{2+}$ additive in the electrolyte, high capacity and excellent long-term cycling ability were simultaneously realized. This work proves that by exploring MOF materials, high-performance aqueous zinc-ion batteries can be achieved.

Acknowledgements The authors appreciate the financial supports from International Science \& Technology Cooperation Program of China (No. 2016YFE0102200), Shenzhen Technical Plan Project (No. JCYJ20160301154114273), National Key Basic Research (973) Program of China (No. 2014CB932400), and Local Innovative and Research Teams Project of Guangdong Pearl River Talents Program (2017BT01N111).

Open Access This article is licensed under a Creative Commons Attribution 4.0 International License, which permits use, sharing, adaptation, distribution and reproduction in any medium or format, as long as you give appropriate credit to the original author(s) and the source, provide a link to the Creative Commons licence, and indicate if changes were made. The images or other third party material in this article are included in the article's Creative Commons licence, unless indicated otherwise in a credit line to the material. If material is not included in the article's Creative Commons licence and your intended use is not permitted by statutory regulation or exceeds the permitted use, you will need to obtain permission directly from the copyright holder. To view a copy of this licence, visit http://creativecommons.org/licenses/by/4.0/.
Electronic supplementary material The online version of this article (https://doi.org/10.1007/s40820-020-00487-1) contains supplementary material, which is available to authorized users.

\section{References}

1. T.-H. Kim, J.-S. Park, S.K. Chang, S. Choi, J.H. Ryu, H.-K. Song, The current move of lithium ion batteries towards the next phase. Adv. Energy Mater. 2(7), 860-872 (2012). https ://doi.org/10.1002/aenm.201200028

2. J.-M. Tarascon, M. Armand, Issues and challenges facing rechargeable lithium batteries. Nature 414(6861), 359-367 (2001). https://doi.org/10.1038/35104644

3. B. Scrosati, J. Hassoun, Y.-K. Sun, Lithium-ion batteries. A look into the future. Energy Environ. Sci. 4(9), ee01388b (2011). https://doi.org/10.1039/c1ee01388b

4. M.A. Hannan, M.M. Hoque, A. Mohamed, A. Ayob, Review of energy storage systems for electric vehicle applications: issues and challenges. Renew. Sustain. Energy Rev. 69, 771789 (2017). https://doi.org/10.1016/j.rser.2016.11.171

5. C. Xu, B. Li, H. Du, F. Kang, Energetic zinc ion chemistry: the rechargeable zinc ion battery. Angew. Chem. Int. Ed. 51(4), 933-935 (2012). https://doi.org/10.1002/anie.201106307

6. H.D. Yoo, I. Shterenberg, Y. Gofer, G. Gershinsky, N. Pour, D. Aurbach, $\mathrm{Mg}$ rechargeable batteries: an on-going challenge. Energy Environ. Sci. 6(8), 2265-2279 (2013). https://doi. org/10.1039/c3ee40871j

7. N. Jayaprakash, S.K. Das, L.A. Archer, The rechargeable aluminum-ion battery. Chem. Commun. 47(47), 12610-12612 (2011). https://doi.org/10.1039/c1cc15779e

8. A. Konarov, N. Voronina, J.H. Jo, Z. Bakenov, Y.-K. Sun, S.-T. Myung, Present and future perspective on electrode materials for rechargeable zinc-ion batteries. ACS Energy Lett. 3(10), 2620-2640 (2018). https://doi.org/10.1021/acsenergyl ett.8b01552

9. M. Song, H. Tan, D. Chao, H.J. Fan, Recent advances in Znion batteries. Adv. Funct. Mater. 28(41), 1802564 (2018). https://doi.org/10.1002/adfm.201802564

10. L. Dong, W. Yang, W. Yang, Y. Li, W. Wu, G. Wang, Multivalent metal ion hybrid capacitors: a review with a focus on zincion hybrid capacitors. J. Mater. Chem. A 7(23), 13810-13832 (2019). https://doi.org/10.1039/c9ta02678a

11. Z. Kang, C. Wu, L. Dong, W. Liu, J. Mou et al., 3D porous copper skeleton supported zinc anode toward high capacity and long cycle life zinc ion batteries. ACS Sustain. Chem. Eng. 7(3), 3364-3371 (2019). https://doi.org/10.1021/acssu schemeng.8b05568

12. K.E. Sun, T.K. Hoang, T.N. Doan, Y. Yu, X. Zhu, Y. Tian, P. Chen, Suppression of dendrite formation and corrosion on zinc anode of secondary aqueous batteries. ACS Appl. Mater. Interfaces 9(11), 9681-9687 (2017). https://doi.org/10.1021/ acsami.6b16560 
13. F. Wang, O. Borodin, T. Gao, X. Fan, W. Sun et al., Highly reversible zinc metal anode for aqueous batteries. Nat. Mater. 17(6), 543-549 (2018). https://doi.org/10.1038/s4156 3-018-0063-Z

14. W. Xu, Y. Wang, Recent progress on zinc-ion rechargeable batteries. Nano-Micro Lett. 11(1), 90 (2019). https://doi. org/10.1007/s40820-019-0322-9

15. H. Pan, Y. Shao, P. Yan, Y. Cheng, K.S. Han et al., Reversible aqueous zinc/manganese oxide energy storage from conversion reactions. Nat. Energy 1(5), 16039 (2016). https://doi. org/10.1038/nenergy.2016.39

16. N. Zhang, F. Cheng, J. Liu, L. Wang, X. Long et al., Rechargeable aqueous zinc-manganese dioxide batteries with high energy and power densities. Nat. Commun. 8(1), 405 (2017). https://doi.org/10.1038/s41467-017-00467-x

17. B. Jiang, C. Xu, C. Wu, L. Dong, J. Li, F. Kang, Manganese sesquioxide as cathode material for multivalent zinc ion battery with high capacity and long cycle life. Electrochim. Acta 229, 422-428 (2017). https://doi.org/10.1016/j.elect acta.2017.01.163

18. W. Liu, J. Hao, C. Xu, J. Mou, L. Dong et al., Investigation of zinc ion storage of transition metal oxides, sulfides, and borides in zinc ion battery systems. Chem. Commun. 53(51), 6872-6874 (2017). https://doi.org/10.1039/c7cc01064h

19. J. Hao, J. Mou, J. Zhang, L. Dong, W. Liu, C. Xu, F. Kang, Electrochemically induced spinel-layered phase transition of $\mathrm{Mn}_{3} \mathrm{O}_{4}$ in high performance neutral aqueous rechargeable zinc battery. Electrochim. Acta 259, 170-178 (2018). https://doi. org/10.1016/j.electacta.2017.10.166

20. C. Zhong, B. Liu, J. Ding, X. Liu, Y. Zhong et al., Decoupling electrolytes towards stable and high-energy rechargeable aqueous zinc-manganese dioxide batteries. Nat. Energy (2020). https://doi.org/10.1038/s41560-020-0584-y

21. X. Guo, J. Zhou, C. Bai, X. Li, G. Fang, S. Liang, Zn/ $\mathrm{MnO}_{2}$ battery chemistry with dissolution-deposition mechanism. Mater. Today Energy 16, 100396 (2020). https://doi. org/10.1016/j.mtener.2020.100396

22. C. Zhu, G. Fang, S. Liang, Z. Chen, Z. Wang et al., Electrochemically induced cationic defect in $\mathrm{MnO}$ intercalation cathode for aqueous zinc-ion battery. Energy Storage Mater. 24, 394-401 (2020). https://doi.org/10.1016/j.ensm.2019.07.030

23. P. Hu, T. Zhu, J. Ma, C. Cai, G. Hu et al., Porous $\mathrm{V}_{2} \mathrm{O}_{5}$ microspheres: a high-capacity cathode material for aqueous zinc-ion batteries. Chem. Commun. 55(58), 8486-8489 (2019). https:// doi.org/10.1039/c9cc04053f

24. F. Wan, L. Zhang, X. Dai, X. Wang, Z. Niu, J. Chen, Aqueous rechargeable zinc/sodium vanadate batteries with enhanced performance from simultaneous insertion of dual carriers. Nat. Commun. 9(1), 1656 (2018). https://doi.org/10.1038/s4146 7-018-04060-8

25. Y. Cai, F. Liu, Z. Luo, G. Fang, J. Zhou, A. Pan, S. Liang, Pilotaxitic $\mathrm{Na}_{1.1} \mathrm{~V}_{3} \mathrm{O}_{7.9}$ nanoribbons/graphene as high-performance sodium ion battery and aqueous zinc ion battery cathode. Energy Storage Mater. 13, 168-174 (2018). https:// doi.org/10.1016/j.ensm.2018.01.009
26. D. Chao, C.R. Zhu, M. Song, P. Liang, X. Zhang et al., A highrate and stable quasi-solid-state zinc-ion battery with novel $2 \mathrm{D}$ layered zinc orthovanadate array. Adv. Mater. 30(32), 1803181 (2018). https://doi.org/10.1002/adma.201803181

27. P. He, G. Zhang, X. Liao, M. Yan, X. Xu et al., Sodium ion stabilized vanadium oxide nanowire cathode for high-performance zinc-ion batteries. Adv. Energy Mater. 8(10), 1702463 (2018). https://doi.org/10.1002/aenm.201702463

28. W. Li, K. Wang, S. Cheng, K. Jiang, A long-life aqueous Zn-ion battery based on $\mathrm{Na}_{3} \mathrm{~V}_{2}(\mathrm{PO} 4)_{2} \mathrm{~F}_{3}$ cathode. Energy Storage Mater. 15, 14-21 (2018). https://doi.org/10.1016/j. ensm.2018.03.003

29. Q. Su, X. Cao, T. Yu, X. Kong, Y. Wang et al., Binding $\mathrm{MoSe}_{2}$ with dual protection carbon for high-performance sodium storage. J. Mater. Chem. A 7(40), 22871-22878 (2019). https://doi.org/10.1039/C9TA06870H

30. L. Zhang, L. Chen, X. Zhou, Z. Liu, Towards high-voltage aqueous metal-ion batteries beyond $1.5 \mathrm{~V}$ : the zinc/zinc hexacyanoferrate system. Adv. Energy Mater. 5(2), 1400930 (2015). https://doi.org/10.1002/aenm.201400930

31. R. Trocoli, F. La Mantia, An aqueous zinc-ion battery based on copper hexacyanoferrate. ChemSusChem 8(3), 481-485 (2015). https://doi.org/10.1002/cssc.201403143

32. Z. Liu, G. Pulletikurthi, F. Endres, A prussian blue/zinc secondary battery with a bio-ionic liquid-water mixture as electrolyte. ACS Appl. Mater. Interfaces 8(19), 12158-12164 (2016). https://doi.org/10.1021/acsami.6b01592

33. M.S. Chae, J.W. Heo, S.C. Lim, S.T. Hong, Electrochemical zinc-ion intercalation properties and crystal structures of $\mathrm{ZnMo}_{6} \mathrm{~S}_{8}$ and $\mathrm{Zn}_{2} \mathrm{Mo}_{6} \mathrm{~S}_{8}$ chevrel phases in aqueous electrolytes. Inorg. Chem. 55(7), 3294-3301 (2016). https://doi. org/10.1021/acs.inorgchem.5b02362

34. L. Li, Q. Zhao, Z. Luo, Y. Lu, H. Ma et al., High-capacity aqueous zinc batteries using sustainable quinone electrodes. Sci. Adv. 4(3), eaa01761 (2018). https://doi.org/10.1126/ sciadv.aao 1761

35. G. Dawut, Y. Lu, L. Miao, J. Chen, High-performance rechargeable aqueous $\mathrm{Zn}$-ion batteries with a poly(benzoquinonyl sulfide) cathode. Inorg. Chem. Front. 5(6), 1391-1396 (2018). https://doi.org/10.1039/c8qi00197a

36. Y. Fu, Q. Wei, G. Zhang, X. Wang, J. Zhang et al., Highperformance reversible aqueous $\mathrm{Zn}$-ion battery based on porous $\mathrm{MnO}_{\mathrm{x}}$ nanorods coated by MOF-derived N-doped carbon. Adv. Energy Mater. 8(26), 1801445 (2018). https:// doi.org/10.1002/aenm.201801445

37. D. Kundu, B.D. Adams, V. Duffort, S.H. Vajargah, L.F. Nazar, A high-capacity and long-life aqueous rechargeable zinc battery using a metal oxide intercalation cathode. Nat. Energy 1(10), 16119 (2016). https://doi.org/10.1038/nener gy.2016.119

38. M.H. Alfaruqi, V. Mathew, J. Song, S. Kim, S. Islam et al., Electrochemical zinc intercalation in lithium vanadium oxide: a high-capacity zinc-ion battery cathode. Chem. Mater. 29(4), 1684-1694 (2017). https://doi.org/10.1021/ acs.chemmater.6b05092 
39. L. Dong, X. Ma, Y. Li, L. Zhao, W. Liu et al., Extremely safe, high-rate and ultralong-life zinc-ion hybrid supercapacitors. Energy Storage Mater. 13, 96-102 (2018). https:// doi.org/10.1016/j.ensm.2018.01.003

40. X. Xie, S. Liang, J. Gao, S. Guo, J. Guo et al., Manipulating the ion-transfer kinetics and interface stability for highperformance zinc metal anodes. Energy Environ. Sci. 13(2), 503-510 (2020). https://doi.org/10.1039/c9ee03545a

41. S. Higashi, S.W. Lee, J.S. Lee, K. Takechi, Y. Cui, Avoiding short circuits from zinc metal dendrites in anode by backside-plating configuration. Nat. Commun. 7, 11801 (2016). https://doi.org/10.1038/ncomms11801

42. Y. Tang, C. Liu, H. Zhu, X. Xie, J. Gao et al., Ion-confinement effect enabled by gel electrolyte for highly reversible dendrite-free zinc metal anode. Energy Storage Mater. 27, 109-116 (2020). https://doi.org/10.1016/j.ensm.2020.01.023

43. C. Li, X. Xie, S. Liang, J. Zhou, Issues and future perspective on zinc metal anode for rechargeable aqueous zincion batteries. Energy Environ. Mater. (2020). https://doi. org/10.1002/eem2.12067

44. H. Furukawa, K.E. Cordova, M. O'Keeffe, O.M. Yaghi, The chemistry and applications of metal-organic frameworks. Science 341(6149), 1230444 (2013). https://doi. org/10.1126/science.1230444

45. B.Y. Guan, X.Y. Yu, H.B. Wu, X.W.D. Lou, Complex nanostructures from materials based on metal-organic frameworks for electrochemical energy storage and conversion. Adv. Mater. 29(47), 1703614 (2017). https://doi. org/10.1002/adma.201703614

46. H. Wang, Q.-L. Zhu, R. Zou, Q. Xu, Metal-organic frameworks for energy applications. Chem 2(1), 52-80 (2017). https://doi.org/10.1016/j.chempr.2016.12.002

47. J.W. Choi, D. Aurbach, Promise and reality of post-lithiumion batteries with high energy densities. Nat. Rev. Mater. 1(4), 16013 (2016). https://doi.org/10.1038/natrevmats .2016 .13

48. P. Simon, Y. Gogotsi, Materials for electrochemical capacitors. Nat. Mater. 7(11), 845-854 (2008). https://doi.org/10.1038/ nmat 2297

49. E.D. Wachsman, K.T. Lee, Lowering the temperature of solid oxide fuel cells. Science 334(6058), 935-939 (2011). https:// doi.org/10.1126/science. 1204090

50. Z. Wang, J. Hu, L. Han, Z. Wang, H. Wang et al., A MOFbased single-ion $\mathrm{Zn}^{2+}$ solid electrolyte leading to dendritefree rechargeable Zn batteries. Nano Energy 56, 92-99 (2019). https://doi.org/10.1016/j.nanoen.2018.11.038

51. Z. Cui, Q. Liu, C. Xu, R. Zou, J. Zhang et al., A new strategy to effectively alleviate volume expansion and enhance the conductivity of hierarchical MnO@C nanocomposites for lithium ion batteries. J. Mater. Chem. A 5(41), 21699-21708 (2017). https://doi.org/10.1039/c7ta05986h

52. H. Hu, X. Lou, C. Li, X. Hu, T. Li et al., A thermally activated manganese 1,4-benzenedicarboxylate metal organic framework with high anodic capability for Li-ion batteries. New J. Chem. 40(11), 9746-9752 (2016). https://doi.org/10.1039/ c6nj02179d
53. K.M.L. Taylor-Pashow, J.D. Rocca, Z. Xie, S. Tran, W. Lin, Postsynthetic modifications of iron-carboxylate nanoscale metal-organic frameworks for imaging and drug delivery. J. Am. Chem. Soc. 131(40), 14261-14263 (2009). https://doi. org/10.1021/ja906198y

54. X. Hu, H. Hu, C. Li, T. Li, X. Lou, Q. Chen, B. Hu, Cobaltbased metal organic framework with superior lithium anodic performance. J. Solid State Chem. 242, 71-76 (2016). https:// doi.org/10.1016/j.jssc.2016.07.021

55. T. Kim, H. Kim, T.-S. You, J. Kim, Carbon-coated $\mathrm{V}_{2} \mathrm{O}_{5}$ nanoparticles derived from metal-organic frameworks as a cathode material for rechargeable lithium-ion batteries. J. Alloys Compd. 727, 522-530 (2017). https://doi.org/10.1016/j.jallc om.2017.08.179

56. S. Maiti, A. Pramanik, U. Manju, S. Mahanty, Reversible lithium storage in manganese 1,3,5-benzenetricarboxylate metalorganic framework with high capacity and rate performance. ACS Appl. Mater. Interfaces. 7(30), 16357-16363 (2015). https://doi.org/10.1021/acsami.5b03414

57. D. Wu, Z. Guo, X. Yin, Q. Pang, B. Tu et al., Metal-organic frameworks as cathode materials for $\mathrm{Li}^{-\mathrm{O}_{2}}$ batteries. Adv. Mater. 26(20), 3258-3262 (2014). https://doi.org/10.1002/ adma.201305492

58. T. Yamada, K. Shiraishi, H. Kitagawa, N. Kimizuka, Applicability of MIL-101 (Fe) as a cathode of lithium ion batteries. Chem. Commun. 53(58), 8215-8218 (2017). https://doi. org/10.1039/c7cc01712j

59. W. Yan, Z. Guo, H. Xu, Y. Lou, J. Chen, Q. Li, Downsizing metal-organic frameworks with distinct morphologies as cathode materials for high-capacity $\mathrm{Li}_{2} \mathrm{O}_{2}$ batteries. Mater. Chem. Front. 1(7), 1324-1330 (2017). https://doi.org/10.1039/c6qm0 0338a

60. B. He, Q. Zhang, P. Man, Z. Zhou, C. Li et al., Self-sacrificed synthesis of conductive vanadium-based metal-organic framework nanowire-bundle arrays as binder-free cathodes for highrate and high-energy-density wearable $\mathrm{Zn}$-ion batteries. Nano Energy 64, 103935 (2019). https://doi.org/10.1016/j.nanoe n. 2019.103935

61. Z. Zhang, H. Yoshikawa, K. Awaga, Monitoring the solid-state electrochemistry of $\mathrm{Cu}(2,7-\mathrm{aqdc})$ (aqdc $=$ anthraquinone dicarboxylate) in a lithium battery: coexistence of metal and ligand redox activities in a metal-organic framework. J. Am. Chem. Soc. 136(46), 16112-16115 (2014). https://doi.org/10.1021/ ja508197w

62. Z.-P. Feng, G.-R. Li, J.-H. Zhong, Z.-L. Wang, Y.-N. Ou, Y.-X. Tong, $\mathrm{MnO}_{2}$ multilayer nanosheet clusters evolved from monolayer nanosheets and their predominant electrochemical properties. Electrochem. Commun. 11(3), 706-710 (2009). https:// doi.org/10.1016/j.elecom.2009.01.001

63. H. Zhu, Q. Liu, J. Liu, R. Li, H. Zhang, S. Hu, Z. Li, Construction of porous hierarchical manganese dioxide on exfoliated titanium dioxide nanosheets as a novel electrode for supercapacitors. Electrochim. Acta 178, 758-766 (2015). https://doi. org/10.1016/j.electacta.2015.08.073

64. B. Thirupathi, P.G. Smirniotis, Nickel-doped $\mathrm{Mn} / \mathrm{TiO}_{2}$ as an efficient catalyst for the low-temperature SCR of NO with 
$\mathrm{NH}_{3}$ : catalytic evaluation and characterizations. J. Catal. 288, 74-83 (2012). https://doi.org/10.1016/j.jcat.2012.01.003

65. A.L. Reddy, M.M. Shaijumon, S.R. Gowda, P.M. Ajayan, Coaxial $\mathrm{MnO}_{2} /$ carbon nanotube array electrodes for highperformance lithium batteries. Nano Lett. 9(3), 1002 (2009). https://doi.org/10.1021/n1803081j

66. W. Chen, G. Li, A. Pei, Y. Li, L. Liao et al., A manganesehydrogen battery with potential for grid-scale energy storage. Nat. Energy 3(5), 428-435 (2018). https://doi.org/10.1038/ s41560-018-0147-7

67. L. Xu, E.-Y. Choi, Y.-U. Kwon, Ionothermal synthesis of a 3D Zn-BTC metal-organic framework with distorted tetranuclear $\left[\mathrm{Zn}_{4}\left(\mu_{4}-\mathrm{O}\right)\right]$ subunits. Inorg. Chem. Commun. 11(10), 11901193 (2008). https://doi.org/10.1016/j.inoche.2008.07.001

68. Y. Huang, J. Mou, W. Liu, X. Wang, L. Dong, F. Kang, C. $\mathrm{Xu}$, Novel insights into energy storage mechanism of aqueous rechargeable $\mathrm{Zn} / \mathrm{MnO}_{2}$ batteries with participation of $\mathrm{Mn}^{2+}$. Nano-Micro Lett. 11(1), 49 (2019). https://doi.org/10.1007/ s40820-019-0278-9

69. R. Zhang, X.R. Chen, X. Chen, X.B. Cheng, X.Q. Zhang, C. Yan, Q. Zhang, Lithiophilic sites in doped graphene guide uniform lithium nucleation for dendrite-free lithium metal anodes. Angew. Chem. Int. Ed. 56(27), 7764-7768 (2017). https://doi.org/10.1002/anie.201702099

70. L. Fan, H.L. Zhuang, W. Zhang, Y. Fu, Z. Liao, Y. Lu, Stable lithium electrodeposition at ultra-high current densities enabled by 3D PMF/Li composite anode. Adv. Energy Mater. 8(15), 1703360 (2018). https://doi.org/10.1002/aenm.20170 3360

71. X.B. Cheng, R. Zhang, C.Z. Zhao, Q. Zhang, Toward safe lithium metal anode in rechargeable batteries: a review. Chem. Rev. 117(15), 10403-10473 (2017). https://doi.org/10.1021/ acs.chemrev.7b00115

72. J.W. Gallaway, D. Desai, A. Gaikwad, C. Corredor, S. Banerjee, D. Steingart, A lateral microfluidic cell for imaging electrodeposited zinc near the shorting condition. J. Electrochem. Soc. 157(12), 1279-1286 (2010). https://doi. org/10.1149/1.3491355

73. K.N. Wood, E. Kazyak, A.F. Chadwick, K.H. Chen, J.G. Zhang, K. Thornton, N.P. Dasgupta, Dendrites and pits: untangling the complex behavior of lithium metal anodes through operando video microscopy. ACS Cent. Sci. 2(11), 790-801 (2016). https://doi.org/10.1021/acscentsci.6b00260
74. J.F. Parker, C.N. Chervin, E.S. Nelson, D.R. Rolison, J.W. Long, Wiring zinc in three dimensions re-writes battery performance-dendrite-free cycling. Energy Environ. Sci. 7(3), 1117-1124 (2014). https://doi.org/10.1039/c3ee43754j

75. L. Kang, M. Cui, F. Jiang, Y. Gao, H. Luo et al., Nanoporous $\mathrm{CaCO}_{3}$ coatings enabled uniform $\mathrm{Zn}$ stripping/plating for longlife zinc rechargeable aqueous batteries. Adv. Energy Mater. 8(25), 1801090 (2018). https://doi.org/10.1002/aenm.20180 1090

76. Z. Zhao, J. Zhao, Z. Hu, J. Li, J. Li et al., Long-life and deeply rechargeable aqueous $\mathrm{Zn}$ anodes enabled by a multifunctional brightener-inspired interphase. Energy Environ. Sci. 12(6), 1938-1949 (2019). https://doi.org/10.1039/c9ee00596j

77. M. Cui, Y. Xiao, L. Kang, W. Du, Y. Gao et al., Quasi-isolated $\mathrm{Au}$ particles as heterogeneous seeds to guide uniform $\mathrm{Zn}$ deposition for aqueous zinc-ion batteries. ACS Appl. Energy Mater. 2(9), 6490-6496 (2019). https://doi.org/10.1021/acsae m.9b01063

78. M. Chamoun, W.R. Brant, C.-W. Tai, G. Karlsson, D. Noréus, Rechargeability of aqueous sulfate $\mathrm{Zn} / \mathrm{MnO}_{2}$ batteries enhanced by accessible $\mathrm{Mn}^{2+}$ ions. Energy Storage Mater. 15, 351-360 (2018). https://doi.org/10.1016/j.ensm.2018.06.019

79. X. Wu, Y. Xiang, Q. Peng, X. Wu, Y. Li et al., A green-lowcost rechargeable aqueous zinc-ion battery using hollow porous spinel $\mathrm{ZnMn}_{2} \mathrm{O}_{4}$ as the cathode material. J. Mater. Chem. A 5(34), 17990-17997 (2017). https://doi.org/10.1039/ c7ta00100b

80. B. Tang, G. Fang, J. Zhou, L. Wang, Y. Lei et al., Potassium vanadates with stable structure and fast ion diffusion channel as cathode for rechargeable aqueous zinc-ion batteries. Nano Energy 51, 579-587 (2018). https://doi.org/10.1016/j.nanoe n.2018.07.014

81. V. Augustyn, J. Come, M.A. Lowe, J.W. Kim, P.L. Taberna et al., High-rate electrochemical energy storage through $\mathrm{Li}^{+}$ intercalation pseudocapacitance. Nat. Mater. 12(6), 518-522 (2013). https://doi.org/10.1038/nmat3601

82. G. Fang, Z. Wu, J. Zhou, C. Zhu, X. Cao et al., Observation of pseudocapacitive effect and fast ion diffusion in bimetallic sulfides as an advanced sodium-ion battery anode. Adv. Energy Mater. 8(19), 1703155 (2018). https://doi.org/10.1002/ aenm.201703155 